\title{
LEAPS Therapeutic Vaccines as Antigen Specific Suppressors of Inflammation in Infectious and Autoimmune Diseases
}

\author{
Daniel H Zimmerman ${ }^{1 *}$, Harold Steiner III ${ }^{1}$, Roy Carmabula ${ }^{1}$, Eyal Talor ${ }^{1}$ and Ken S Rosenthal ${ }^{2}$ \\ ${ }^{1}$ CEL-SCI Corporation 8229 Boone Blvd suite 802 Vienna, VA 22182, USA \\ ${ }^{2}$ Integrative Medical Sciences, NEOMED State Road 44, Rootstown, Ohio, 44272, USA
}

\begin{abstract}
The L.E.A.P.S. TM (Ligand Epitope Antigen Presentation System) technology platform has been used to develop immunoprotective and immunomodulating small peptide vaccines for infectious and autoimmune diseases. Severa products are currently in various stages of development, at the pre-clinical stage (in animal challenge efficacy studies). Vaccine peptides can elicit protection of animals from lethal viral (herpes simplex virus [HSV-1] and influenza A) infection or can block the progression of autoimmune diseases (e.g. rheumatoid arthritis as in the collagen induced arthritis (CIA] or experimental autoimmune myocarditis (EAM) models). L.E.A.P.S. technology is a novel T-cell immunization technology that enables the design and synthesis of non-recombinant, proprietary peptide immunogens. Combination of a small peptide that activates the immune system with another small peptide from a disease-related protein, thus a conjugate containing both an Immune Cell Binding Ligand (ICBL) and a disease specific epitope, which allows the L.E.A.P.S. vaccines to activate precursors to differentiate and become more mature cells that can initiate and direct appropriate T cell responses. As such, readily synthesized, defined immunogens can be prepared to different diseases and are likely to elicit protection or therapy as applicable in humans as they are in mice. L.E.A.P.S. vaccines have promise for the treatment of rheumatoid arthritis and other inflammatory diseases and for infections, such as influenza and HSV1. The protective responses are characterized as Th1 immune and immunomodulatory responses with increased IL-12p70 and IFN- $\gamma$ (Th1 cytokines) but reduced inflammatory cytokines TNF- $\alpha$, IL-1 and IL-17 (Th2 and Th17 cytokines) and concomitant changes in antibody subtypes. LEAPS immunogens have been used directly in vivo or as ex vivo activators of DC which are then administered to the host.
\end{abstract}

Keywords: Vaccines; Peptide; Immune response; Mode of action; Dendritic cell; T cells; Cytokines; Antiviral vaccines; Autoimmunity

\section{Introduction}

The major goal for preparing a successful vaccine is to elicit the proper immune response to the antigen of interest without eliciting inappropriate immune responses either to the antigen of interest or other antigens in the preparation. This problem arises because every protein is a collection of potential immunogenic epitopes and antigens, some of which may elicit protection while others may elicit excessive inflammation or even suppression of desired immune responses. Common solutions to this problem include use of minimal immunogenic epitopes or to administer a minimal amount of material in the vaccine. Unfortunately, this often results in use of peptides which are either too small to be immunogenic or otherwise deficient in eliciting the desired and appropriate immune responses as many small peptide antigens elicit only an improper or weak response. Our goal when we started work on the LEAPS ${ }^{m}$ (Ligand Epitope Antigen Presentation System) technology in 1987 was to focus the immune response on an immunogenic peptide and direct the nature of the response to one that is appropriate for the disease to be prevented or treated. The treatment may induce a humoral or cellular response, defined by Th1, Th2, Th17, Treg, Tc (T cytotoxic cell), Ts (T suppressor cell) or other type of T cell, still to be defined.

The immunogenicity of small peptides can be enhanced in different ways including making multimers, by attaching lipids, and with peptides that promote binding of the epitope to MHC II molecules, such as the Padre or Ii-Key technologies [1], to facilitate their presentation to T cells. For the Padre technique, the immunogenic epitope peptide is covalently attached to a peptide that binds tightly to MHC II molecules (Pan DR binding) while the Ii-Key conjugate enhances binding by linking a peptide epitope to a modified portion of the invariant chain that binds tightly to the outside of the epitope binding cleft of $\mathrm{MHC}$
II molecules on the surface of cells. Both approaches increase the immunogenicity of a peptide but usually do not change the nature of the response.

The LEAPS technology platform has been used to develop immunoprotective and immunomodulating small peptide vaccines for infectious and autoimmune diseases. The LEAPS vaccines combine a small peptide that activates the immune system (originally referred to as a $\mathrm{T}$ cell binding ligand TCBL) with another small peptide containing a disease-related peptide containing an epitope [2,3]. The LEAPS peptide heteroconjugate vaccine technology was first conceived and a patent disclosure statement filed in 1987 and converted into a patent application in 1988 which issued in 1996. In 1987, the state of the art was much less advanced and our understanding of T cells was limited, antigen presenting cells (APC) included macrophages and B cells, and knowledge of dendritic cells (DCs) was in its infancy and naïve. For perspective, toll like receptors (TLR) were only well known for insects. With the recognition of the importance of DCs to the initiation and direction of immune responses we [4,5] demonstrated that at least one of the TCBL molecules, (referred to as J), activates precursor DCs

*Corresponding author: Daniel H Zimmerman, CEL-SCI Corporation 8229 Boone Blvd suite 802 Vienna, VA 22182, USA, E-mail: dzimmerman@cel-sci.com

Received August 16, 2012; Accepted September 20, 2012; Published September 20, 2012

Citation: Zimmerman DH, Steiner HIII, Carmabula R, Talor E, Rosenthal KS (2012) LEAPS Therapeutic Vaccines as Antigen Specific Suppressors of Inflammation in Infectious and Autoimmune Diseases. J Vaccines Vaccin 3:147. doi:10.4172/21577560.1000149

Copyright: (c) 2012 Zimmerman DH, et al. This is an open-access article distributed under the terms of the Creative Commons Attribution License, which permits unrestricted use, distribution, and reproduction in any medium, provided the original author and source are credited. 
to become semi-mature DCs so that the TCBL term has now been redefined and broadened to ICBL (immune cell binding ligand).

Several products are currently in various stages of development, at the pre-clinical stage in animal immunogenicity, delayed type hypersensitivity (DTH), mode of action (MOA) and challenge efficacy studies. LEAPS vaccines incorporating peptides from viruses can induce protection of animals from lethal viral infectious challenge (herpes simplex virus [HSV-1] [5-7] and influenza A virus [8]) as a prophylactic or therapeutic agent or can block the progression of autoimmune diseases in appropriate mouse models of disease (e.g. rheumatoid arthritis as in the collagen induced arthritis model [CIA] [9] or experimental autoimmune myocarditis model [EAM] [10]). In addition, LEAPS vaccines with the J-ICBL can induce human monocytes to differentiate into DCs and initiate immune responses [4]. LEAPS vaccines can be readily prepared as GMP (Good Manufacturing Practice) materials and contain no radioactive, toxic or infectious materials. As such, these readily synthesized, defined immunogens can be prepared to different diseases in advance and are likely to elicit protective or therapeutic responses as applicable in humans as they have been demonstrated to do in mice.

The LEAPS technology approach chemically links a peptide containing a disease associated epitope through a triglycine linker to a peptide that targets or binds to an antigen presenting cell such as a DC or to a $\mathrm{T}$ cell, combining adjuvant/activating and antigen/immunizing activities into one relatively small peptide (Figure 1) [2,3,9,11].

The ICBL of the LEAPS vaccines consists of a small peptide from a protein that interacts with cell activating receptors on immune cells and is covalently attached to the immunogenic peptide through a triglycine linker. The J ICBL consists of a peptide from the beta2-microglobulin component of MHC-I (aa 38-50: DLLKNGERIEKVE) [12] and the derG peptide consists of a peptide from the beta chain of MHC-II (aa 135-149: NGQEEKAGVVSTGLI) [13,14]. Another less frequently used ICBL is from IL-1 $\beta$ 163-171 $[2,3,15]$. Figure 1 , illustrates examples of LEAPS conjugates attached to an epitope containing peptide from HSV-1 glycoprotein D 8-23. Although the ICBL is at the N-terminus of most LEAPS (as indicated in Figure 1), we have evaluated peptides with the ICBL at the $\mathrm{C}$ terminus with no major differences in activity. Also, it has been our experience that for full function and consistent long term effect, the peptides (ICBL and antigenic peptide) must be conjugated.

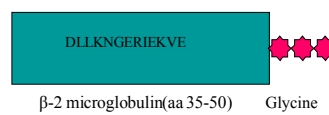

(J)

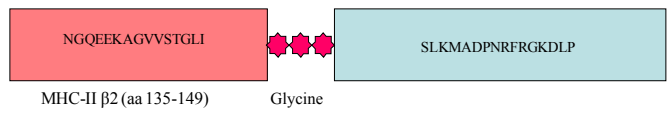

(G)

\section{J LEAPS functions:}

* Confers immunogenicity to T cell epitopes.

* Initiates prime-boost type of response.

Directs response to $\mathrm{TH} 1$ as determined cytokines (Increases in first IL-12p70, and ultimately IFN $\gamma$ ) and IgG2a subtype antibody production.

Figure 1: Examples of LEAPS vaccines.

The J-ICBL or the G-ICBL is attached to an HSV epitope $(\mathrm{gD})$ through a triglycine linker.
The J-ICBL directs new immune responses to be Th1 and upon a boost with protein, Th1 associated antibodies (IgG2a) are generated. J-LEAPS vaccines with peptides from $M$. tuberculosis $[3,16]$ and HIV $[2,15,17,18]$ elicit Th1 related immune responses as determined by preferential IgG2a and DTH responses and J-LEAPS vaccines with several different HSV $\mathrm{T}$ cell epitope containing peptides [4-7,11] elicited protection from lethal challenge and similar DTH and preferential IgG2a Th1 responses. The J-LEAPS peptide, [2,11,15,19] can promote the maturation of human or mouse precursors into a unique DC (LEAPS-DC) which produces IL-12p70 but not TNF- $\alpha$ or IL1 [4,5]. LEAPS-DCs are sufficient to initiate and immunize mice to elicit protection from lethal HSV challenge [5] and to protect and modulate the onset of ongoing influenza disease [8] in mouse models. Human monocytes treated with J-LEAPS conjugates incorporating immunogenic peptides from either HSV or HIV converted into semimature DC capable of initiating an allogeneic (mixed lymphocyte response) IFN- $\gamma$ associated Th1 like response [4].

Another ICBL, derG, is derived from the $\beta$ chain of human MHC class II protein $[2,3,15,18,20]$ but this ICBL promotes the production of Th2 responses, including cytokines and preference for IgG1 antibody. It is likely that derG-LEAPS vaccines may be able to modulate an ongoing immune response and be beneficial in certain instances.

J-LEAPS vaccines can block the progression of autoimmune diseases by immunomodulation of ongoing pathogenic responses. Immunomodulation of the Th17 response during RA with a J-LEAPS vaccine (CEL-2000) that incorporates a peptide from type II collagen blocks the progression of collagen induced arthritis (CIA) [9]. Another J-LEAPS vaccine blocked the progression of experimental autoimmune myocarditis (EAM) in a mouse model [10]. Similarly, J-LEAPS vaccines modulated the inflammatory cytokine response to influenza, curtailing the cytokine storm induced by the virus [8]. Inflammatory cytokines, such as TNF- $\alpha$, IL-1, IL-6, and IL-17 were lowered with modest increases in IFN- $\gamma$ and IL-12p70.

In this review, we will discuss the activity of several different LEAPS vaccines in detail, vaccines for modulation of ongoing, or initiation of new immune responses as demonstrated in the EAM, CIA, HSV and influenza disease models. In each case, only vaccines with the J ICBL were protective when such an efficacy evaluation was possible. Vaccines containing the same immunogenic peptides but attached to the derG/G ICBL promoted Th2 humoral responses. The derG/G-ICBL vaccines were not protective and had either no effect or exacerbated the diseases. These vaccines generated different cytokine profiles (confirmed in preliminary experiments) than the J-ICBL vaccines and IgG isotypes preferences (IgG1>IgG 2a in the mouse). The LEAPS vaccine peptides or DCs prepared with the LEAPS peptides were evaluated in appropriate mouse models for each of the diseases.

\section{EAM - experimental autoimmune myocarditis as a model for myocarditis}

Although most cases of myocarditis are related to viral infection, there is some connection between persistent infections and autoimmune inflammation of the cardiac tissues. There are several models for myocarditis for which the pathology that develops resembles in part the human condition [21-23]. The experimental autoimmune myocarditis (EAM) mouse model has several advantages and benefits from being induced by a well-defined autoantigen of the target organ, either murine cardiac myosin in some mouse strains or just the Myl peptide $\left(\mathrm{MyHCa}_{334-352}\right)$ for the $\mathrm{A} / \mathrm{J}$ strain. 
Citation: Zimmerman DH, Steiner H, Carmabula R, Talor E, Rosenthal KS (2012) LEAPS Therapeutic Vaccines as Antigen Specific Suppressors of Inflammation in Infectious and Autoimmune Diseases. J Vaccines Vaccin 3:147. doi:10.4172/2157-7560.1000149

The EAM murine model used in the LEAPS studies was induced by s.c. injection of the My-1 peptide with complete Freund's adjuvant (CFA) and pertussis adjuvant on day 0 followed on day 7 with My-1 emulsified (1:1) with incomplete Freund's adjuvant (ICFA) only. Disease progression could be monitored as early as day 10 or on days 21 or 28 for heart and body weight, heart histopathology, cytokines (from serum, spleen, and heart) and serum antibodies for myosin and the BCG antigens in the adjuvant. Mice with EAM display a characteristic enlargement of the heart (Figure 2) with noticeable lymphocyte infiltration of the cardiac tissue compared to either normal hearts or mice preimmunized with J-My-1 (not shown). A more detailed examination of mice treated prophylactically or therapeutically with J-My-1 showed that J-My-1 did not induce disease and that J-My-1 pretreated mice appeared to be protected based on either the heart to body weight ratio or the extent of cardiac histopathology compared to

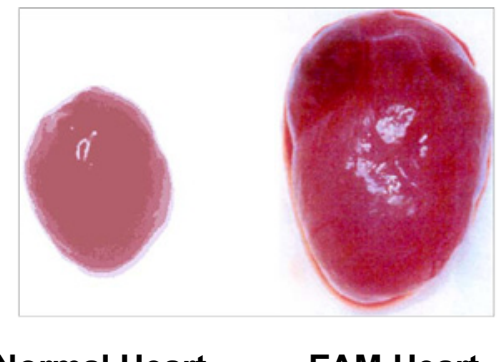

\section{Normal Heart EAM Heart}

Figure 2: LEAPS and experimental autoimmune myocarditis Hearts from normal A/J (left) mouse and a littermate induced to develop EAM, as described in the materials and methods (right). Hearts from mice $(n=20)$ pretreated with J-MY-1 prior to induction of EAM were indistinguishable from the normal heart.
PBS-treated mice [10]. The most significant change in the immunized mice was in the levels of the chemokines IP-10 and MIP1 $\alpha$, which were decreased in the hearts of J-My-1 treated animals. It has been similarly shown in other studies that these chemokines are critical to the induction of EAM [23]. As in the control mice, antibody against the mycobacterium (BCG) elements of the complete Freund's adjuvant was still produced and no differences seen in antibody to $\mathrm{My}-1$ produced in the LEAPS vaccinated mice. One incident of anaphylaxis was observed in a couple of mice in this study using very young animals (around 3-4 weeks of age) with immature immune systems and the use of 3 or more weekly doses of vaccine [10]. Anaphylaxis in young mice has also been seen by others in other systems but, as will be described later, older mice are much less prone to this complication and this is also manageable by modification of the peptide or with drugs reducing substantially the potential for anaphylaxis [24-29]. These results support the hypothesis that LEAPS conjugates modulate the immune response against the antigenic portion of the conjugate in an antigen specific manner via chemokines, cytokines and cells but not by changes in antibody and do not appear to induce general tolerance or anergy. The advantages to this approach over more traditional modes of immunosuppression are: use of a single defined epitope without the involvement of other selfantigens; efficacy as a treatment after the disease was induced; and that the effect was epitope specific with no global immunosuppressive effect on other and concurrent immune responses, e.g. to the mycobacterium elements of the complete Freund's adjuvant.

\section{CIA - collagen induced arthritis as a model rheumatoid arthritis}

Rheumatoid Arthritis (RA) is an autoimmune disorder affecting millions of people worldwide, and is characterized by systemic inflammation and progressive joint deterioration. While steroids,

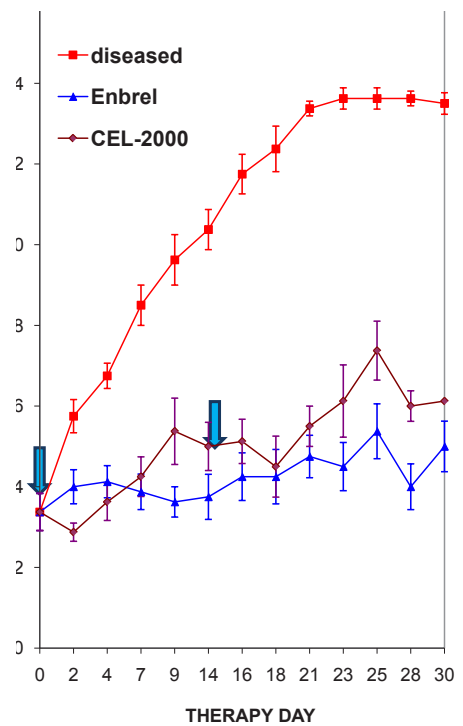

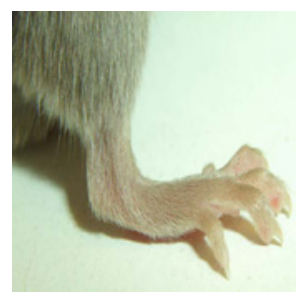

Non diseased score 0

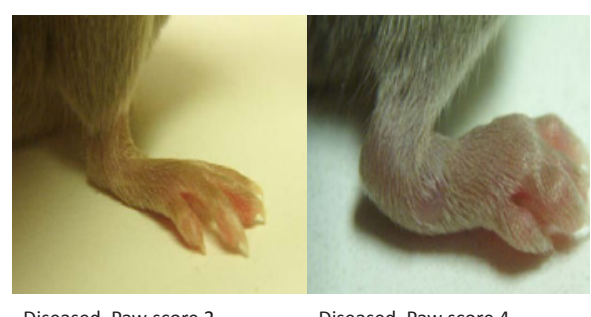

Diseased Paw score 2

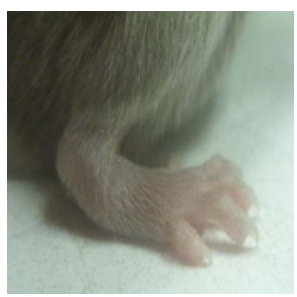

Diseased Paw score

Diseased Paw score 4

Figure 3: Disease progression of untreated and CEL-2000 treated collagen-induced arthritis (CIA) mice.

A. Arthritic Index (AI) of CIA mice ( $n=8)$. DBA/1J mice (7-8 week old males) received 2 injections $100 \mu$ g bovine collagen, the first emulsified with CFA (day 0 ) and then 3 weeks later (day 21), in IFA. On day 31, the mice were grouped to have a balanced range of scores between 1 and 6 per group with a mean score $\sim 3.5$.

Therapy was initiated after grouping of mice on day 31 of study. J-LEAPS conjugate CEL-2000 (100nmol) was administered in ISA51vg adjuvant (courtesy

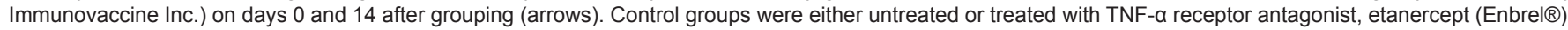
Chart shows average $\mathrm{Al}$ and standard deviation.

B. Examples of hind limbs of CIA-affected mice. Severity is scored on a scale of 1-4 for each paw, with a maximum score of 16 per animal. Representative paws with the indicated clinical score are shown. 


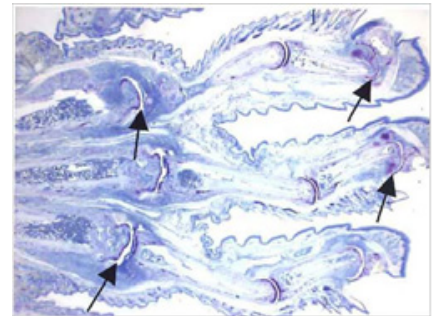

Untreated Disease Paw

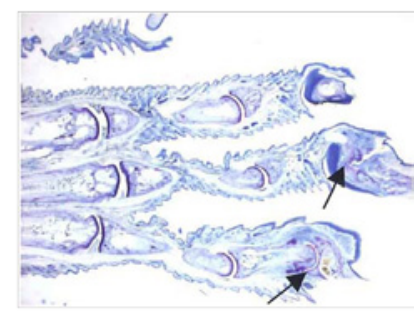

CEL-2000 Treated Paw
Figure 4: Histology of joints from CEL-2000 treated and untreated mice following induction of CIA.

$16 \mathrm{x}$ Photomicrographs of hind paws of representative CIA mice at end of study (day 60) untreated (left) or treated with LEAPS (right). Arrows indicate affected joints.

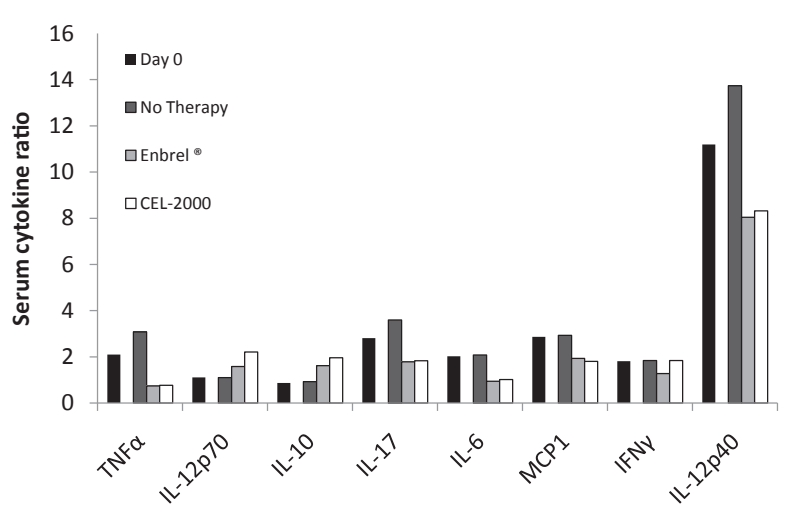

Figure 5: $\mathrm{CIA}$ associated serum cytokines.

Serum from CIA induced DBA/1J mice was collected on days 0 and 10 of therapy tested by protein array analysis, represented as a ratio of densitometry results relative to results for VEGF. Groups $(n=8)$ were untreated, treated with Enbrel every other day, or immunized with 33nmol CEL-2000 in MAS-1 (another adjuvant from MerciPharma, and has similar action to ISA51vg)day 0 Adapted from [9].

anti-inflammatory drugs including NSAIDS, and disease-modifying antirheumatic drugs (DMARDs) are an important part of current therapeutic strategies, the most recent advances in treatment have come from biologics targeting specific components of the immunological inflammatory pathway. Unfortunately, many current RA therapies have significant drawbacks: Some, such as methotrexate, are toxic, while others, such as the biologics, have potentially severe side effects, and put the recipient at higher risk to infection. None of these are universally effective and they are directed more to alleviate the symptoms rather than to address the underlying cause of the disease. The LEAPS conjugate used in this model, CEL-2000, combines the J-ICBL with an epitope of type II collagen, noted to have T-cell responsiveness in human RA patients $\left(\mathrm{CII}_{254-273}\right.$, or CIIx) [30,31].

There are many recognized models of autoimmune arthritis in animals [32-34], each in different species, with different methods and agents for inducing disease, and even differences in disease manifestation and progression. Some models differ significantly from the human condition in promoting rapid progression of disease. The collagen-induced arthritis (CIA) model was used to demonstrate the ability of a J-LEAPS conjugate to therapeutically treat RA [9]. In the CIA model, disease is induced by immunizing DBA mice with bovine type II collagen emulsified with CFA on day 0 and collagen in IFA on day 21. Unlike in the EAM study, the prophylactic efficacy of the CIA
J-LEAPS vaccines was not evaluated since prophylactic vaccines for RA would not be useful or a marketable product. Treatment with a J-LEAPS vaccine was initiated as therapy around day 31 , after the onset of disease symptoms as determined by AI score. The LEAPS conjugate used in this model, CEL-2000, combines the J-ICBL with an epitope of type II collagen, noted to have T-cell responsiveness in human RA patients $\left(\mathrm{CII}_{254-273}\right.$, or CIIx) [30,31].

Mice with CIA develop notable swelling and inflammation of the paws and ankles (Figure 3), including cell infiltration and destruction of the joints. Mice treated with CEL-2000 (J-CIIx) had much less swelling of the paws as measured by an arthritic index (AI) score compared to untreated mice. The efficacy indicated by the favorable AI score (Figure 3 panel A) [9] was similar to therapy with etanercept (Enbrel'), an antiTNF- $\alpha$ biologic used in the clinic to treat RA in man and considered the therapeutic "gold standard". At the end of the study histopathological examination of ankles and paws following treatment also showed a lack of disease progression due to vaccination that blocked bone or cartilage erosion and damage, prevented panus membrane formation and inflammation, see legend and arrows in (Figure 4) We also showed using older mice (about 4-8 weeks before start of therapy versus normally around 10 days to 2 weeks after second induction immunization on day 21). These DBA/1J mice tolerated 5 injections over a 90 day period (approximately every two weeks with no adverse effects and showed control of disease based on the AI score (not shown).

The effect of CEL-2000 on disease progression was indicated by serum cytokine levels evaluated on serum taken 10 days after initiation of therapy. Analysis of serum cytokines in treated and untreated mice showed a redirection away from the Th17 response (untreated) and towards a Th1 response (CEL-2000 treated) (Figure 5), with a relative decrease in inflammatory cytokines TNF- $\alpha$ and IL-17, but an increase in IL-12p70, IFN- $\gamma$ and IL-10. Other affected molecules of note showed decreases e.g. IL-12p40, IL-6, and MCP-1. The increase in IL-12p70 but decrease in IL-12p40 suggests a decrease in IL-23, an inducer of the Th17 response, while the decrease in IL- 6 and MCP-1 suggest a decrease in T-cell proliferation and recruitment to the synovium. There is no decrease in the overall antibody response to collagen, and only a modest increase of the Th1-like IgG2a/IgG1 ratio (suggesting class switching) (see Figure 8), the total sum of effects on AI score, histopathology and serum levels of inflammatory and Th1 cytokines suggests a decrease in the maintenance and severity of the inflammatory response. Conceptually this method of immune modulation is preferable to anti-cytokine or receptor blocking as it actively redirects the immune response away from the pathological response, rather than generically removing an important component of the immune system. The anti-cytokine and receptor blocking approach are not selective and can delete essential protections against tuberculosis (TB), cancers, etc, for which TNF- $\alpha$, other cytokines or the ablated cell-cell interaction is a required component of the immune response, putting the treated individual at risk to these diseases.

\section{HSV-1 (Herpes Simplex Virus type 1)}

Herpes simplex virus (HSV) is a ubiquitous virus affecting an estimated 40-60 million Americans with approximately 600,000 new cases occurring per year $[35,36]$. HSV-type 1 (HSV-1) is a common oral pathogen and closely related to HSV type 2 (HSV-2). HSV-1 and HSV-2 cause primary and recurrent oral and genital infections [3740] and also infect other parts of the body, cause serious disease of the eye, encephalitis, and life threatening neonatal disease. While closely related and sharing many common antigens, there are also major differences between HSV-1 and HSV-2 in the viral glycoproteins and 
A

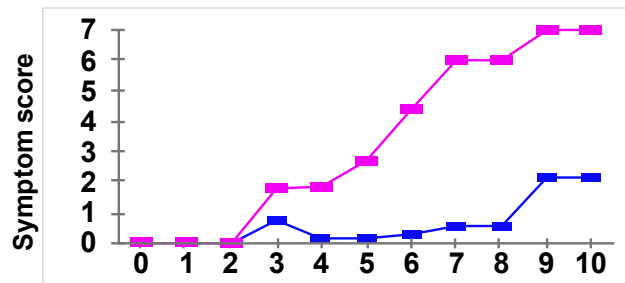

B

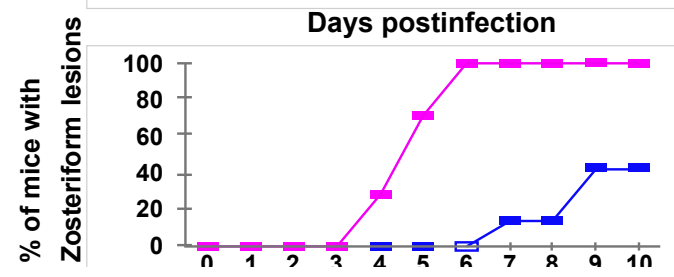

C

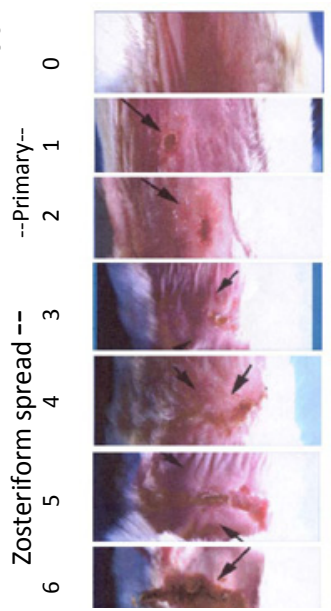

Figure 6: JgD immunization prevents the progression of HSV zosteriform disease.

Comparison of disease progression in unvaccinated and mice vaccinated with the JgD vaccine and then challenged with $\mathrm{HSV}-1 \mathrm{H} 129\left(6 \times 10^{4}\right.$ pfu) by epidermal abrasion. Mice were observed for lesion development for up to 10 days post-infection. Lesion score: scores of 1 or 2 indicates local site lesions; score $\geq 3$ indicates progression to secondary site (zoster spread); score of 7 indicates death. JgD vaccinated mice had significantly (Student's t-test $P<0.05)$ lower disease symptoms (from day 3) as compared to the Seppic ISA-51 treated control mice (A), and fewer mice were affected by zosteriform lesions (B). (C) Representative photographs of control (Top, not infected) and unvaccinated infected mice exhibiting zosteriform lesions (middle) to severe (score of 6) at the bottom..

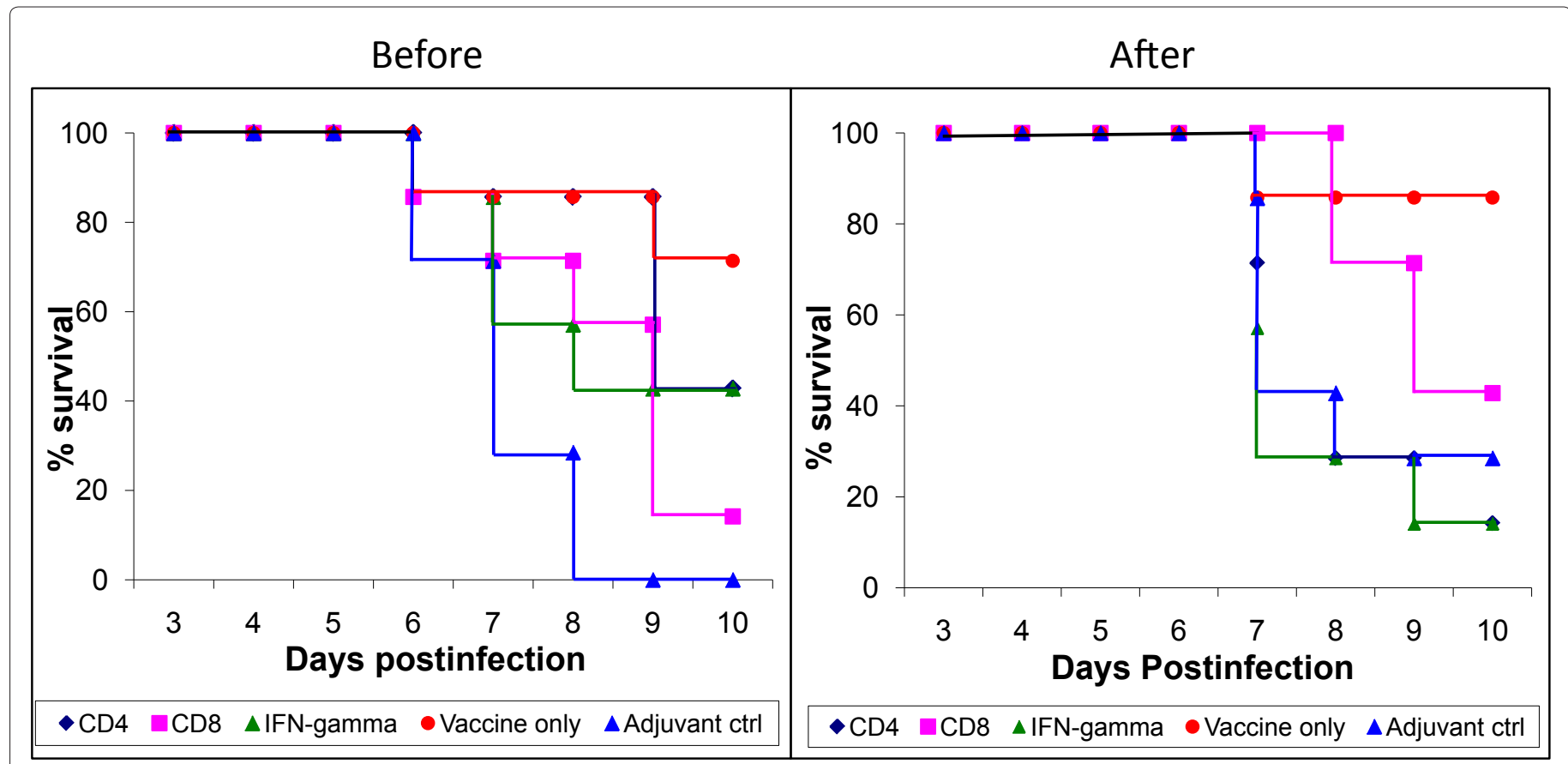

Figure 7: Monoclonal antibody ablation of immune components during the induction or effector phases of immunity to JgD

Mice were immunized on day 0 and 21 with $\mathrm{JgD}$ vaccine in adjuvant or with adjuvant alone. Before the initial immunization or before the viral challenge as appropriate, select groups $(n=7)$ of mice were treated with monoclonal antibodies to CD4, CD8, IFN-Y or control serum $[6,18]$. The survival is shown following zosteriform HSV-1 viral challenge. Ablating antibody may remain present during the challenge period.

their action on DCs [41]. Current anti-viral therapy is effective at reducing the severity of the symptoms but does not prevent or cure the establishment of latency or subsequent flare-ups. Antibody is not sufficient for protection or control of HSV infection such that cross type infection and recurrence of HSV 1 or HSV-2 occurs in the presence of humoral immunity, as evidenced by serum and or secretory antibodies. CD8 T cells are important for controlling the infection and preventing recurrence of the virus. Suppression of cell mediated immunity puts the individual at great risk to more serious primary infection and recurrence of HSV. Indeed it is considered by many that a Th1 type driven cell mediated response is important and sufficient to control the progression of infection [19,42-45].

LEAPS vaccines for HSV-1 were prepared incorporating peptides with CD8 T cell epitopes from 3 major proteins; glycoprotein $\mathrm{B}(\mathrm{gB})$, 
glycoprotein D $(\mathrm{gD})$, and infected early cell nuclear protein of HSV1 27 (ICP27) with the J ICBL and their efficacy was compared to vaccines with the G-ICBL and the unconjugated peptide. These peptides were administered in oil-in water or liposomal adjuvants that establish a depot for slow release of vaccine. The gB and ICP27 (H1) peptides were minimal $\mathrm{T}$ cell epitopes of 8-9 amino acids. The JgD vaccine used a slightly larger peptide (15 vs 9 amino acid). With the JH1 immunogen (ICP27 vaccine), we established that LEAPS vaccines can establish protective immunity by activating $\mathrm{T}$ cell responses without the need for antibody [19] and this was confirmed with JgB.

Figure 6 shows typical results for C57BL/6 mice that were unimmunized or immunized twice with a 2 week interval with the JgD vaccine and then two weeks later, received lethal HSV challenge by dermal abrasion. For unimmunized mice, zosteriform lesions began to appear on day 3 and all mice had zosteriform lesions by day 6 and had died by day $9,[46]$ whereas only 3 mice developed lesions which were much reduced in JgD immunized mice and all animals survived. The zosteriform spreading is a function of both the virus neurotropic capabilities to invade, progress up the dorsal root ganglia and back down the axons of other neurons and the host's immune, inflammatory and repair responses [46]. JgD elicited protection in mice of various strains with different MHC backgrounds (H2d: Balb/c, H2b: C57BL/6, H2k: C3H, H2q: FVB) [6].

Vaccines with the G-ICBL (GH1 and GgB) had no effect with regard to protection, survival or zosteriform spread and were likely to have exacerbated the disease due to their potential to activate non-protective and inhibitory $\mathrm{Th} 2$ responses.

The relative roles of CD4 and CD8 T cells and IFN- $\gamma$ during immunization with JgD and the protection (effector) phases were determined by monoclonal antibody ablation studies. Antibody ablation prior to immunization indicated that CD8+ cells were absolutely needed to establish immunity less important for protection during the effector phase of immunity, while both $\mathrm{CD} 4+$ cells and IFN- $\gamma$ were needed in either the effector or both phases (Figure 7) [6]. At the time of the experiments, it could not be determined whether the CD8 bearing cells in the mice were DCs or T cells, but subsequent studies indicated the importance of CD8 bearing DCs for initiation of JgD immunity in mice [5].

Additional hints to the nature of the immune response elicited by $\mathrm{JgD}$, was obtained by analysis of cytokines present in serum following immunization. Serum was collected from JgD treated mice (C57BL/6 or A/J female) (immunized once) and pooled on days 3, 10 and 24 post treatment and 22 cytokines were evaluated on a RayBiotech cytokine array (See Taylor et al., figure 1, panel A) [5]. Statistical analysis of the results (sequential Bonferroni correction for multiple contrasts) showed a significant $(\mathrm{p}<0.01) \mathrm{JgD}$ induced change (vs. adjuvant control) in the following cytokines: IL-12p70, IL-12p40, RANTES, MCP-5, IL-2, IFN- $\gamma$, IL-17 and MCP-1 (see Taylor et al., 2010, figure1, panel B) [5]. Mice treated with the J-ICBL alone showed only a change in IL-10 levels [5].

$\mathrm{JgD}$ and another J-LEAPS vaccine, $\mathrm{JH}$, (JH: incorporating a 30 amino acid peptide from HIV-1B clade gag P17) were used to show that J-LEAPS vaccines promote the maturation and activate mouse bone marrow cell suspensions from immune-naïve mice to become DCs with increased levels of expression of MHC II, CD86, and CD11c within 4896 hours (see Taylor et al., 2010, figure 3, panels A and B) [5]. Previous studies had shown spleen cells (either immunized on unimmunized) to be unresponsive to $\mathrm{JgD}$ or $\mathrm{JH}$. In a separate experiment (see Taylor et al., 2010, Figure 3, panels A and B) [5], CD3+ cells were removed
A) CIA

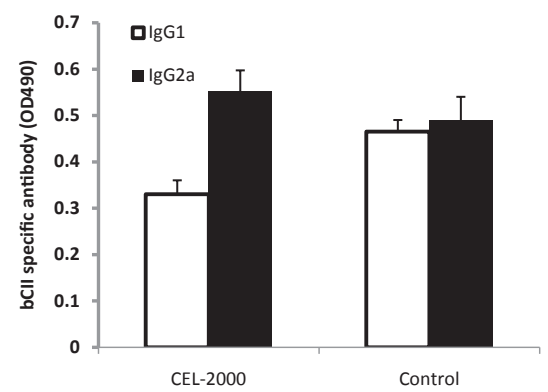

C) EAM

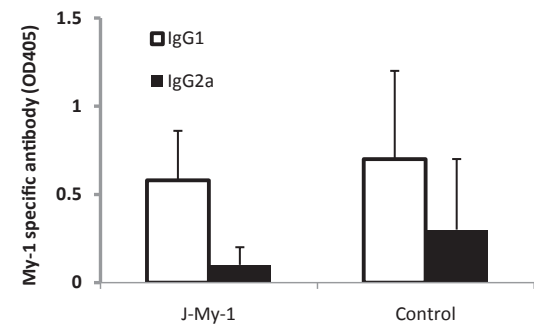

B) HSV

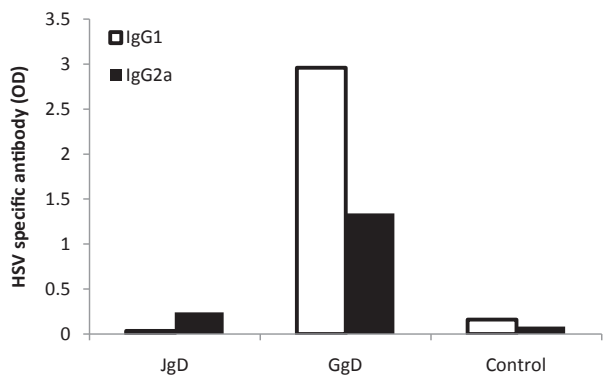

D) HSV Specificity

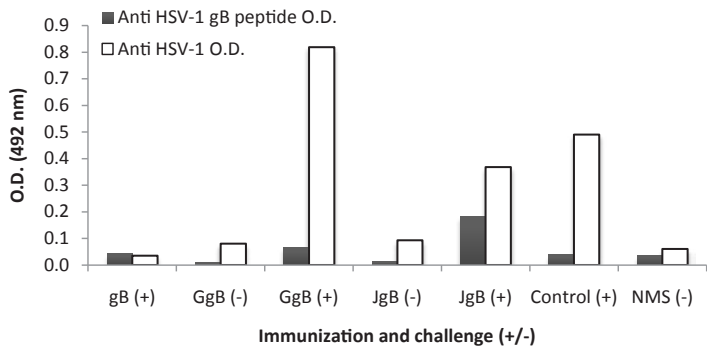

Figure 8: Characterization of antibody isotypes and specificity after $\mathrm{J}$ or $\mathbf{G}$ (derG)-LEAPS vaccine immunization and antigen challenge. Panel A. Antibodies generated in CEL-2000 immunized or unimmunized mice in the CIA model, adapted from [9].

Panel B. Antibodies generated after HSV infection of animals immunized with JgD, adapted from [6].

Panel C. Antibodies generated following immunization with J-MY1, adapted from [10].

Panel D. Antibodies produced by HSV infected mice following immunization with HSV JgB, GgB or gB, adapted from [7]. 
from the BM prior to treatment with JgD. After 24 hours, $12 \%$ of the control cells expressed low levels of CD8 and less than $3 \%$ of these cells were positive for IL- $12 \mathrm{p} 70$ but at $48 \mathrm{~h}$, the JgD treated CD3- population contained $73 \%$ CD8 positive, IL-12p70 producing cells, and the $\mathrm{JH}$ treated CD3- population contained $72 \%$ CD8 positive, IL- $12 p 70$ producing cells [5]. Murine CD8 expressing DCs are most important for cross presentation of antigen and activation of CD8 T cells [47]. Taylor et al. further showed that while co-cultures of $\mathrm{JH}$ treated and JgD activated DCs with murine splenic T cells (not from immunized mice) could stimulate low levels of IFN- $\gamma$, the antigen specific T murine cells produced much more IFN- $\gamma$, indicating antigen specificity of the interaction $[4,5]$.

In a related series of experiments, human monocytes were treated with either JgD or JH and these cells also differentiated into DCs with up regulation of MHC II and CD86. The JgD-DCs were able to initiate production of IFN- $\gamma$ in an allogenic T cell response [5]. Treatment of the human monocytes with JgD converted the cells into IL12 producing DCs that could initiate a Th1 T cell response in a similar manner to the mouse bone marrow cells, indicating that J-LEAPS vaccines should elicit similar immune responses in humans.

In order to demonstrate that JgD induces the development of semimature functional DCs, the DCs must be able to initiate a new immune response in a naïve mouse. Bone marrow cells treated with JgD for $24 \mathrm{~h}$ (JgD-DC) were washed to remove free JgD and injected intradermally and intraperitoneally into immunonaive mice on two occasions at one week intervals. The adoptive transfer of JgD-DC was sufficient to initiate antigen specific protection against disease and death whereas control mice that did not receive cells (naïve) or those that received JH-DC or untreated DC had extensive morbidity and mortality (see Taylor et al., 2010, Figure 7) [5]. These studies demonstrated that JgDDCs are functional semi-mature DCs and with production of IL-12p70, generated a protective Th1 response. These studies also demonstrated the potential use of J-LEAPS vaccines to prepare dendritic cell vaccines for adoptive transfer.

\section{PR8 as a Model of Influenza A - H1N1}

Seasonal influenza A viruses cause significant morbidity and mortality particularly in the young and old, killing more than 250,000 worldwide each year while generating a significant economic burden to millions [48]. All currently licensed influenza vaccines rely on the antigenicity of the very immunogenic but highly variable and strain specific hemagglutinin (HA) and neuraminidase (NA) envelope glycoproteins. There are at least 17 different HA and 9 different NA serotypes for influenza A. Furthermore, influenza A viruses are genetically unstable because of both drifts (mutations) and shifts (gene exchange through reassortment during infection with multiple strains) to produce new sub-strains or clades of virus. Antibody, including that elicited by the annual vaccines, to these proteins provides extreme pressure for mutations and changes in the HA and NA antigens of the virus. Influenza vaccines containing the appropriate mixture of HAs and NAs are configured annually to protect against the strains of virus predicted to be in the environment based on global influenza surveillance $[49,50]$. Unfortunately the prediction is not always successful and the consequences can be dire.

A universal influenza vaccine that can elicit protection against most or all strains of influenza is desired. This vaccine perhaps would have to generate antibodies to conserved and protective sequences in the HA or NA glycoproteins or elicit T cell responses to the highly conserved internal proteins of the virus, such as polymerases, proteases, nucleoproteins and matrix proteins. Indeed, several conserved epitopes of these proteins have been identified [51-62,63] and are vaccine candidates [64]. The need for such a universal vaccine has been stressed by the events of the last dozen years with pandemics of H5N1 in 2005 and H1N1 in 2009 and with the enhanced potential for spread of the virus due to the consolidation of the world through globalization (including emigration, travel and commerce). Therefore, such, LEAPS vaccines to elicit $\mathrm{T}$ cell responses to influenza were investigated.

Capitalizing on the ability of J-LEAPS vaccines to elicit immunogenic DCs, data shows that selected conserved influenza A antigenic peptides conjugated to the J-ICBL can generate LEAPS-DCs that will provide using treatment to curtail the development of viral and immune-pathogenesis (Not shown). DCs treated with J-LEAPS vaccines containing $\mathrm{CD} 8 \mathrm{~T}$ cell epitopes from influenza proteins were activated and matured, as indicated by immunophenotype, and generated protective cytokine responses. Adoptive immunotherapy using a pooled mixture of these DCs delivered after lethal challenge with $\mathrm{H} 1 \mathrm{~N} 1$ influenza acted rapidly to protect the mice from morbidity and mortality; the mice maintained their weight, showed decreased virus load, and a decrease of inflammatory cytokines compared to untreated (or JH control treated) mice, which died within 7-10 days [8].

\section{Characterization of the J-LEAPS and derG / G Associated Antigen Specific Antibodies}

Before we summarize these findings and proceed we will look at the antibody responses generated in the various systems. J and G conjugates of the LEAPS $38 \mathrm{kDa} \mathrm{TB}$ and HSV protein $\mathrm{gD}$ epitopes $[3,6,7]$ favored production of IgG2a antibodies after protein boost or infection (class switching from IgG1 to IgG2a), G (or derG) conjugates promoted production of IgG1 antibodies. In the mouse, Th1 responses promote IgG2a production and Th2 responses promote IgG1. Similar polarizations of IgG isotype production were seen for J LEAPS CIA, HSV gD, and gB (not shown), (Figure 8A-C) and two different J-LEAPS conjugates with different influenza antigens (data not shown). In the EAM case, there remained a predilection for IgG1. The IgG1 may represent antibody produced to a very unique epitope or perhaps due to a limited clonality of the response. In Panel D, it is seen that immunization with $\mathrm{JgB}$ and $\mathrm{GgB}$ also enhanced isotype antibody responses of infected mice to antigens other than the gB peptide (in the LEAPS conjugate). Similarly, when influenza J- LEAPS-DCs were used for treatment of influenza infected mice, the isotype switch to IgG2a was observed even though the treatment occurred several days after infection and therefore immunization was already initiated, and was also polyclonal in nature (Not shown).

\section{Summary}

Over the course of our studies we have examined over 13 different disease related epitopes, all except the last 4 from influenza A virus included conjugates with both J and G or derG ICBLs. The J-LEAPS vaccines promoted the production of Il-12p70, IFN- $\gamma$ (Th1) directed immune responses, including immunomodulatory responses, Th1 (IgG2a in mouse) associated antibodies and Th1 protective responses and reduced Th-2 or Th-17 responses. These efficacy studies, done mainly for HSV-1 but also for EAM, CIA and Influenza A challenge models plus immunogenicity studies for TB and HIV were done, in 8 inbred and 3 outbred strains of mice of different MHC backgrounds. This indicates the LEAPS technology is effective in multiple MHC backgrounds, a necessary requirement for human use. Conjugates with other ICBLs were not protective in efficacy models (HSV-1, EAM, CIA) possibly because they induce non-protective immune responses 


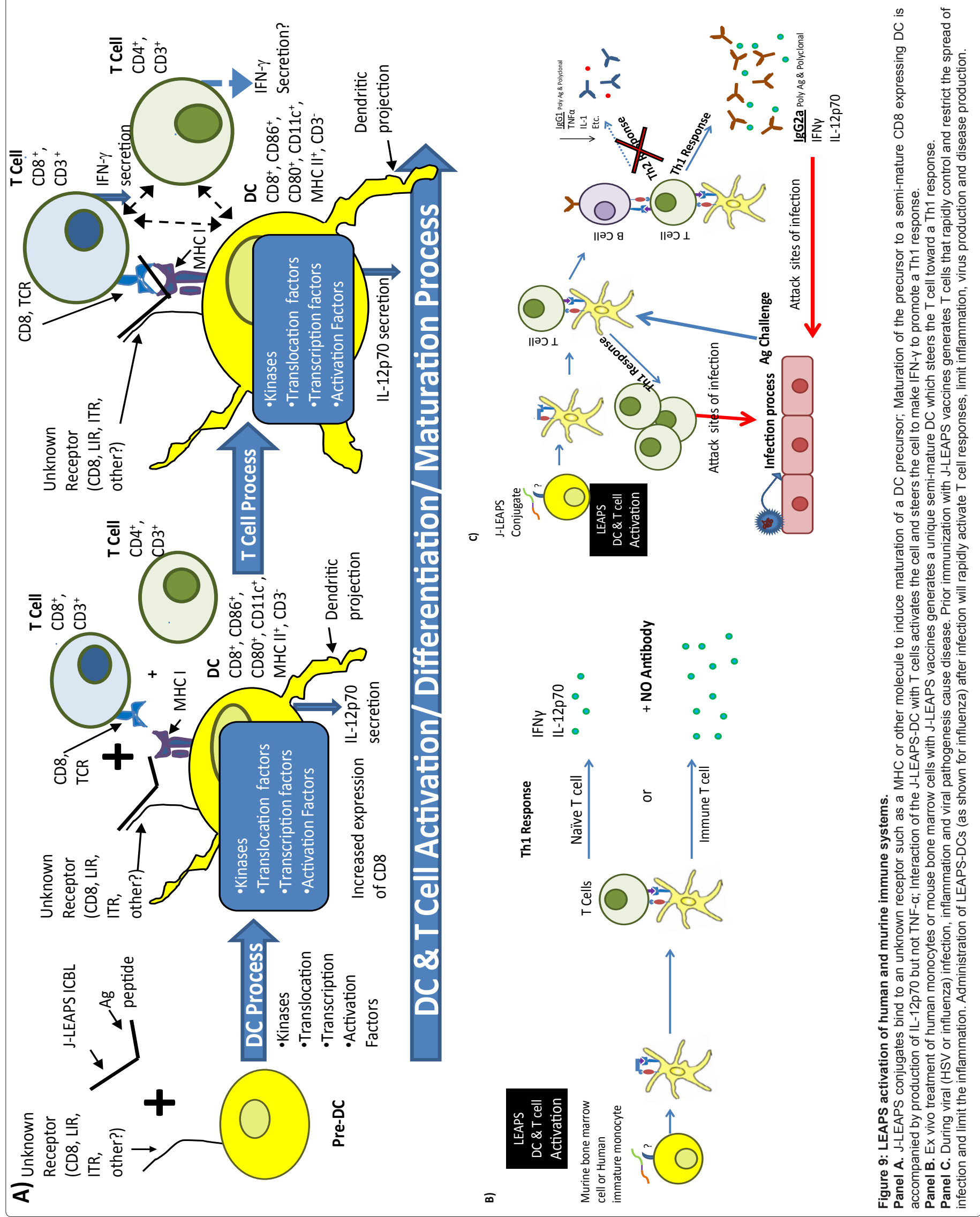


(e.g. Th2 or Th17) or contained an inappropriate epitope for the ICBL in the conjugate. Immunogenicity was demonstrated to several of the J-LEAPS vaccines but a disease model was not available to us to determine whether they would elicit protection or therapy (e.g. HIV or TB). Most of the LEAPS vaccine development is now focused on T cell epitope containing conjugates with the J-ICBL rather than the G-ICBL (also closely related derG, also called CEL-1000) or other ICBLs. Future studies will also include determination of the molecular basis by which the J-LEAPS vaccines activate precursors to become DCs that can activate protective and therapeutic $\mathrm{T}$ cell responses.

\section{Discussion}

Vaccines are used to educate and train the immune response in a safe, effective and controlled manner to deal properly with infectious challenges that can cause potentially pathogenic effects including death in the untreated host. More recently vaccines have also been considered for reeducating immunity, as may be necessary for anticancer vaccines; retraining an aberrant immune response, as occurs during autoimmune diseases; or redirecting immune responses to block or control biological processes, e.g. anti-angiotensin vaccines. For infectious diseases, attenuated vaccines mimic infection and activate the natural innate responses, including DCs, that transition to immune responses to elicit cell mediated (Th17, Th1) and antibody immune (Th1, Th2, etc.) responses. Killed and whole, subunit or recombinant protein vaccines are limited mainly to generation of only Th2 mediated antibody responses. This is mainly due to the means by which the vaccine is delivered, a bolus of antigen, and the adjuvant used in the immunization, the FDA approved alum-like adjuvants. Newer adjuvants mimic activators of DCs to promote broader and better immune responses. The J-LEAPS vaccines act like both an adjuvant (increasing response) and an immunogen (being antigen specific) and like some adjuvants, will act on DCs to direct the immune response in a preferred direction. However, the LEAPS vaccines still require a depot for slow release and recruitment of DC precursors so that they can promote the maturation of these cells.

Vaccine adjuvants are frequently selected based on their ability to induce an immune response towards, or away from, a specific T-helper phenotype, Th1, Th17, or Th2, to promote protective and to limit harmful actions. In the case of the LEAPS vaccines, the ICBL portion of the conjugate is the primary means of directing the phenotypic spectrum rather than an adjuvant. The J-ICBL appears to promote Thl responses to infections while modulating Th17 and inflammatory responses to autoimmune diseases. The G-ICBL promotes Th2 responses.

Unlike most vaccine technologies, the J-LEAPS vaccines can activate new or modulate existing antigen specific immune responses, including autoimmune responses by promoting the maturation of a special type of DC that produces IL-12p70 without the proinflammatory TNF- $a$ cytokine. LEAPS vaccine treatment of CIA and prevention and treatment of EAM in mouse models of these diseases demonstrated antigen specific immunomodulation.

The mechanisms and modes of action by which LEAPS vaccines initiate new and modulate ongoing immune responses remains a subject of inquiry [11]. Representative animal models continue to be used to demonstrate the efficacy of LEAPS vaccines and dissect their mechanisms of action to initiate protection against infection or modulate the progression of autoimmune diseases. The animal models were chosen to ensure that nature of the disease, e.g. location, initiating agent, mechanism of initiation, time of onset and progression of disease, most resembles the human disease and allows vaccine intervention.
Proposed mechanisms for LEAPS activation of DC and resultant immune responses are presented in cartoon form (adapted from Rosenthal et al., 2012) [11]. The current hypothesis for the J-ICBL is: Conjugates of a peptide containing a CD8 T cell epitope linked to the J-ICBL initiates activation by binding to a receptor on a precursor cell to promote its maturation to a unique, semi-mature $\mathrm{DC}$, as shown by surface marker changes. Semi-mature dendritic cells can also promote immunomodulatory tolerance [65] but have the potential to mature further to promote Th1 or other immune responses (Tc, Ts, Treg). These LEAPS-DCs produce IL-12p70, and present the immunogenic peptide to $\mathrm{T}$ cells to promote IFN- $\gamma$ production and a Th1 response. Interestingly, one aspect that makes the LEAPS-DCs unique is their ability to make IL-12p70 without TNF- $\alpha$. TNF- $\alpha$ is induced by TLR activation of DCs and promotes inflammation. IL-12p70, in the absence of TNF- $\alpha$ appears to activate necessary Th1 responses without excessive and pathogenic inflammatory responses. Th1 responses are required for protection against HSV and other viral diseases. Administration of JgD-DC or J-influenza-DC also activates the protective $\mathrm{T}$ cell response, but without the inflammatory cytokines that usually accompany cell mediated immunity.

Panel A of Figure 9 shows how a J-LEAPS vaccine initiates a T cell immune response by interacting with a receptor on a precursor cell, generating a DC which then activates appropriate T cell responses. Ex vivo (panel B), human monocytes or mouse bone marrow cells can be activated by J-LEAPS vaccines to become semi-mature DCs which can initiate Th1 immune responses. Panel C shows a snap shot in vivo of the immune response to an infectious disease, such as HSV or influenza, and the influence that prior immunization with a J-LEAPS peptide or LEAPS-DC can have on the resultant immune response, including antibodies and cytokines. These cytokines define the nature of the T cell help for immunoglobulin class switching as indicated by the bias towards IgG2a for J-LEAPS vaccine induced Th1 responses and IgG1 for G-LEAPS vaccine induced Th2 responses.

Representative animal models were used to demonstrate the efficacy of LEAPS vaccines towards CIA and EAM autoimmune diseases. Like the natural disease, the murine CIA model for RA has a relatively slow onset and progression, one in which therapeutic immunomodulation can be initiated, as demonstrated by CEL-2000, and can have an effect before irreversible tissue damage occurs. In this disease model, we were able to demonstrate that reduction in the inflammatory mediators, IL-17 and TNF- $\alpha$, correspond with the block in disease progression by CEL-2000. Whether the immunomodulation that was observed represents tolerance or anergy or possibly a redefinition of the nature of the autoreactive T cells from Th17 to Treg-like or Th1 cells cannot be said at this time. The lack of a concomitant increase in IFN- $\gamma$ suggests that Th1 cells were not being generated from the Th17 cells. The more aggressive and faster developing EAM disease model may have limited our ability to see all of the changes induced by J-My1 that occurred to modulate the inflammatory disease, but consistent chemokine and cytokine changes were observed. Polarization of T-cell helper phenotypes often involves balance of competitive cytokines. Ultimately, the presence of antigen presenting, unique LEAPS-DCs will initiate new patterns of cytokines that will influence the activities of the T-cell populations.

Unlike most vaccine technologies, by promoting the maturation of a special type of DC that produces IL-12p70 without the proinflammatory TNF- $\alpha$ cytokine, the LEAPS vaccines can activate new or modulate existing antigen specific immune responses, including autoimmune responses. LEAPS vaccine treatment of RA and prevention and 
treatment of EAM in mouse models of these diseases demonstrates antigen-specific immunomodulation.

The immunogenic peptide within the LEAPS vaccine must contain $\mathrm{T}$ cell epitopes to drive the response. As indicated, the length of the peptide can be as short as 8 amino acids (the minimal size of a CTL epitope) or as long as 33 amino acids (as for JH). For the J-ICBL, the immunogenic peptide appears to require an MHC I binding CD8 T cell epitope. For the G-ICBL, an MHC II binding CD4 T cell epitope appears to be important. T cell epitopes are less variable than antibody recognized epitopes and provide help for $B$ cells that produce antibodies to other epitopes within the same protein (epitope spreading). As such, a single epitope vaccine can initiate a broad based response, especially if followed by a protein challenge, as in the early LEAPS JgB, $\mathrm{GgB}$ and Mtb vaccine studies [3,7]. Even for antibody, monoclonal antibodies are effective as therapies for various infectious and cytokine mediated conditions. Single epitope monoclonal antibody is effective for preventing respiratory syncytial virus infection and single epitope immunotherapies for TNF- $\alpha$, IL-1, and cell receptors can block the progression of disease in animal models and humans. Similarly, LEAPS vaccines with single epitopes or even mixtures of LEAPS vaccines can be effective for eliciting protection and providing therapy.

\section{Future Studies}

The future of LEAPS vaccine studies will proceed in two directions, refinement of the current and development of new LEAPS vaccines against other diseases and determination of the mechanism by which LEAPS vaccines direct and initiate immune responses. While advances have been made in identifying the cells that are activated by J -LEAPS vaccines and there is a literature regarding the G-ICBL [13] , there are still many unanswered issues to solve.

The J-LEAPS vaccines act on murine bone marrow and human monocyte precursors to convert them into DCs but the mechanism by which this occurs is not known. Covalent attachment of the J-ICBL and the immunogenic peptide is required for activity. It is likely that the J-ICBL binds to a specific receptor and the immunogenic peptide binds to another receptor, possibly MHC I or MHC II, to crosslink cell surface receptors and extend the occupancy time of $J$ with its receptor. The receptor for the J-ICBL is under investigation. Activation of kinase and other pathways will follow the binding of J-LEAPS vaccines to change the repertoire of activated transcription factors and gene expression in the cell. Identification of these changes and their time course can provide additional hints to the mechanism of action. Additional studies will determine the ultimate phenotype of the DC generated by J-LEAPS vaccines and how it modulates $\mathrm{T}$ cell function.

\section{Conclusion}

The Ligand Epitope Antigen Presentation System (LEAPS") is a peptide vaccine platform technology that converts minimal peptides into immunogens, and speeds and directs the immune response to these peptides. LEAPS vaccines covalently link a disease related T-cell antigen with a dendritic cell (DC) inducing peptide. LEAPS vaccines are unique in their ability to activate DCs and T-cells to rapidly initiate and deliver protection or therapy. LEAPS vaccines have demonstrated protection against lethal herpes simplex virus (HSV1) and $\mathrm{H} 1 \mathrm{~N} 1$ influenza infection, as a prophylactic or therapeutic agent depending upon whether they are administered pre/post disease initiation. LEAPS vaccines evoke beneficial immune responses to antigens of HIV and Mycobacterium tuberculosis. LEAPS vaccines have also shown efficacy in two models of human autoimmune conditions, preventing/curtailing disease progression in arthritis and myocarditis animal models. Although LEAPS vaccines have not yet been given to humans, they induce human monocytes in vitro to become activated DCs similar to mouse DCs including their cytokine response, which strongly indicates that the LEAPS technology translates to humans. Since LEAPS-activated DCs can elicit a rapid response, they can be administered prophylactically to rapidly initiate protection or after exposure to curtail serious infections as treatment and rescue therapies, as demonstrated in a H1N1 influenza model.

LEAPS peptide and LEAPS-DC vaccines pioneer a new approach to directing $\mathrm{T}$ cell mediated prophylaxis/therapy for influenza (H1N1) and other diseases. Delivering rapid protection and therapy, the LEAPS technology can be a significant alternative to the current inactivated or attenuated influenza multi-strain virus vaccines. This transformative approach has progressed beyond the research phase and LEAPS vaccines would be ready for treating people worldwide, both adults and children, once clinically evaluated and approved by local regulatory authorities.

From a practical point of view, LEAPS vaccines are manufactured from low cost, synthetic, well-characterized, small peptides available in developed and developing countries. These peptides are easy to manufacture under GMP conditions and can be lyophilized, affording these vaccines a long shelf-life. Multiple peptides can be incorporated into a single vaccine for extensive antigenic coverage and to elicit protection in the broadest human population. The LEAPS influenza product can be administered parentally on a large scale basis using current adjuvant technologies approved for peptide and protein vaccines or as an autologous ex vivo LEAPS stimulated cell-based therapy. Extrapolating from these results, it is likely that LEAPS-DC based vaccines can provide therapy, in addition to prophylaxis, for HSV and other diseases such as chronic HBV, HCV, CMV, EBV and HIV.

\section{Acknowledgement}

This work was supported by CEL-SCI Corporation (HIV LEAPS studies), Cel Med Incorporated (tuberculosis LEAPS studies), and in part by NIH grants (HSVstudies Al43107-01 and Al 43107-03; and myocarditis studies 1 R43HL 71352 01A1 to CEL-SCI or NEOMED). We acknowledge the assistance of Mr. Carl Tanner and photographs of feet histopathology by Dr Alison Bendele Bolder Biopath; Dr. Sean O'Neill and Valeria Lowe Washington Biotech CIA feet; and mouse hearts by Dr. Noel Rose, John Hopkins University, School of Medicine, Departments of Pathology and Immunology.

\section{References}

1. Rosenthal KS (2005) Immune peptide enhancement of peptide based vaccines Front Biosci 10: 478-482

2. Zimmerman D, Bergmann K, Rosenthal K and Elliott D (1996) A new approach to T-cell activation: natural and synthetic conjugates capable of activating $T$ cells. Vaccine research. Liebert 5: 91-102.

3. Zimmerman DH, Morris S, Rouse D, Worthington K, Elliott D, et al. (1996) Immunization with peptide heterconjugates primes a $t$ helper cell type 1-associated antibody (IgG2a) response that recognizes the native epitope on the 38-kDA protein of Mycobacterium tuberculosis. Vaccine research. Liebert 5: 103-118.

4. Taylor PR, Paustian CC, Koski GK, Zimmerman DH and Rosenthal KS (2010) Maturation of dendritic cell precursors into IL12-producing DCs by J-LEAPS immunogens. Cellular immunology 262: 1-5

5. Taylor PR, Koski GK, Paustian CC, Bailey E, Cohen PA, et al. (2010) J-LEAPS vaccines initiate murine Th1 responses by activating dendritic cells. Vaccine 28: 5533-5542.

6. Goel N, Rong Q, Zimmerman D, Rosenthal KS (2003) A L.E.A.P.S heteroconjugate vaccine containing a T cell epitope from HSV-1 glycoprotein D elicits Th1 responses and protection. Vaccine 21: 4410-4420. 
Citation: Zimmerman DH, Steiner H, Carmabula R, Talor E, Rosenthal KS (2012) LEAPS Therapeutic Vaccines as Antigen Specific Suppressors of Inflammation in Infectious and Autoimmune Diseases. J Vaccines Vaccin 3:147. doi:10.4172/2157-7560.1000149

7. Goel N, Zimmerman DH and Rosenthal KS (2005) Ligand Epitope Antigen Presentation system vaccines against herpes simplex virus. Frontiers in Bioscience 10: 966-974.

8. Boonnak K, Vogel L, Orandle M, Zimmerman D, Talor E, et al. (2012) Targeting dendritic cells: a novel strategy to treat influenza virus infection. Manuscript submitted.

9. Zimmerman DH, Taylor P, Bendele A, Carambula R, Duzant $Y$, et al. (2010) CEL-2000: A therapeutic vaccine for rheumatoid arthritis arrests disease development and alters serum cytokine/chemokine patterns in the bovine collagen type II induced arthritis in the DBA mouse model. International immunopharmacology 10: 412-421.

10. Cihakova D, Barin JG, Baldeviano GC, Kimura M, Talor MV, et al. (2008) L.E.A.P.S. heteroconjugate is able to prevent and treat experimenta autoimmune myocarditis by altering trafficking of autoaggressive cells to the heart. Int Immunopharmacol 8: 624-633.

11. Rosenthal KS, Taylor P, Zimmerman DH (2012) J-LEAPS peptide and LEAPS dendritic cell vaccines. Microb Biotechnol 5: 203-213.

12. Parham P, Androlewicz MJ, Holmes NJ, Rothenberg BE (1983) Arginine 45 is a major part of the antigenic determinant of human beta 2-microglobulin recognized by mouse monoclonal antibody BBM.1. J Biol Chem 258: 61796186.

13. Konig R, Huang LY, Germain RN (1992) MHC class II interaction with CD4 mediated by a region analogous to the $\mathrm{MHC}$ class I binding site for CD8. Nature 356: 796-798.

14. Cammarota G, Scheirle A, Takacs B, Doran DM, Knorr R, et al. (1992) Identification of a CD4 binding site on the beta 2 domain of HLA-DR molecules. Nature 356: 799-801.

15. Pisarev VM, Parajuli P, Mosley RL, Chavez J, Zimmerman D, et al. (2002) FIt3 ligand and conjugation to IL-1beta peptide as adjuvants for a type 1, T-cell response to an HIV p17 gag vaccine. Vaccine 20: 2358-2368.

16. Walton C, Jube S, Schorlemmer A, Patek P, Zimmerman D, et al. (2010) Ex vivo stimulation assay for $T$-cell responses for tuberculosis using LEAPS-peptide heteroconjugates. Curr Trends in Microbiol 6: 1-12.

17. Zimmerman DH, Lloyd JP, Heisey D, Winship MD, Siwek M, et al. (2001) Induction of cross clade reactive specific antibodies in mice by conjugates of HGP-30 (peptide analog of HIV-1(SF2) p17) and peptide segments of human beta-2-microglobulin or MHC II beta chain. Vaccine 19: 4750-4759.

18. Zimmerman DH, Rosenthal KS (2005) The L.E.A.P.S. approach to vaccine development. Front Biosci 10: 790-798.

19. Rosenthal KS, Mao H, Horne WI, Wright C, Zimmerman D (1999) Immunization with a LEAPS heteroconjugate containing a CTL epitope and a peptide from beta-2-microglobulin elicits a protective and DTH response to herpes simplex virus type 1. Vaccine 17: 535-542.

20. Charoenvit Y, Goel N, Whelan M, Rosenthal KS, Zimmerman DH (2004) CEL1000--a peptide with adjuvant activity for Th1 immune responses. Vaccine 22 2368-2373.

21. Cihakova D, Barin JG, Afanasyeva M, Kimura M, Fairweather D, et al. (2008) Interleukin-13 protects against experimental autoimmune myocarditis by regulating macrophage differentiation. Am J Pathol 172: 1195-1208.

22. Donermeyer DL, Beisel KW, Allen PM, Smith SC (1995) Myocarditis-inducing epitope of myosin binds constitutively and stably to I-Ak on antigen-presenting cells in the heart. J Exp Med 182: 1291-1300.

23. Göser S, Ottl R, Brodner A, Dengler TJ, Torzewski J, et al. (2005) Critical role for monocyte chemoattractant protein-1 and macrophage inflammatory protein1 alpha in induction of experimental autoimmune myocarditis and effective antimonocyte chemoattractant protein-1 gene therapy. Circulation 112: 3400-3407.

24. Pedotti R, Sanna M, Tsai M, DeVoss J, Steinman L, et al. (2003) Severe anaphylactic reactions to glutamic acid decarboxylase (GAD) self peptides in NOD mice that spontaneously develop autoimmune type 1 diabetes mellitus. BMC Immunol 4: 2.

25. Pedotti R, DeVoss JJ, Youssef S, Mitchell D, Wedemeyer J, et al. (2003) Multiple elements of the allergic arm of the immune response modulate autoimmune demyelination. Proc Natl Acad Sci U S A 100: 1867-1872.
26. Leech MD, Chung CY, Culshaw A, Anderton SM (2007) Peptide-based immunotherapy of experimental autoimmune encephalomyelitis without anaphylaxis. Eur J Immunol 37: 3576-3581.

27. Liu E, Yu L, Moriyama H, Eisenbarth GS (2004) Animal models of insulindependent diabetes. Methods Mol Med 102: 195-212.

28. Liu E, Moriyama H, Abiru N, Paronen J, Devendra D, et al. (2004) Preventing peptide-induced anaphylaxis: addition of C-terminal amino acids to produce a neutral isoelectric point. J Allergy Clin Immunol 114: 607-613.

29. Liu E, Moriyama H, Abiru N, Miao D, Yu L, et al. (2002) Anti-peptide autoantibodies and fatal anaphylaxis in NOD mice in response to insulin selfpeptides B:9-23 and B:13-23. J Clin Invest 110: 1021-1027

30. Myers LK, Terato K, Seyer JM, Stuart JM, Kang AH (1992) Characterization of a tolerogenic $T$ cell epitope of type II collagen and its relevance to collageninduced arthritis. J Immunol 149: 1439-1443.

31. Honda A, Ametani A, Matsumoto T, Iwaya A, Kano H, et al. (2004) Vaccination with an immunodominant peptide of bovine type II collagen induces an antiTCR response, and modulates the onset and severity of collagen-induced arthritis. Int Immunol 16: 737-745

32. Kannan K, Ortmann RA, Kimpel D (2005) Animal models of rheumatoid arthritis and their relevance to human disease. Pathophysiology 12: 167-181.

33. Brand DD (2005) Rodent models of rheumatoid arthritis. Comp Med 55: 114 122.

34. Bevaart L, Vervoordeldonk MJ, Tak PP (2010) Evaluation of therapeutic targets in animal models of arthritis: how does it relate to rheumatoid arthritis? Arthritis Rheum 62: 2192-2205

35. Nadelman CM, Newcomer VD (2000) Herpes simplex virus infections. New treatment approaches make early diagnosis even more important. Postgrad Med 107: 189-195, 199-200.

36. Whitley R and Gnann J (1993) The epidemiology and clinical manifestations of herpes simplex virus infections. The human herpes viruses. Raven Press, New York, pp 69-105

37. Gilman SC, Docherty JJ, Clarke A, Rawls WE (1980) Reaction patterns of herpes simplex virus type 1 and type 2 proteins with sera of patients with uterine cervical carcinoma and matched controls. Cancer Res 40: 4640-4647.

38. Docherty JJ, Lohse MA, Dellaria MF, Naugle FP, Mason CW, et al. (1984) Incidence of herpes simplex virus types 1 and 2 in penile lesions of college men. J Med Virol 13: 163-170.

39. Docherty JJ, Trimble JJ, Roman SR, Faulkner SC, Naugle FP, et al. (1985) Lack of oral HSV-2 in a college student population. J Med Virol 16: 283-287.

40. Zimmerman DH, Mundon FK, Croson SE, Henchal LS, Docherty JJ, et al. (1985 Identification and typing of herpes simplex virus types 1 and 2 by monoclonal antibodies, sensitivity to the drug (E)-5-(2-bromovinyl)-2'-deoxyuridine, and restriction endonuclease analysis of viral DNA. J Med Virol 15: 215-222.

41. Peretti S, Shaw A, Blanchard J, Bohm R, Morrow G, et al. (2005) Immunomodulatory effects of HSV-2 infection on immature macaque dendritic cells modify innate and adaptive responses. Blood 106: 1305-1313.

42. York LJ, Giorgio DP, Mishkin EM (1995) Immunomodulatory effects of HSV2 glycoprotein D in HSV1 infected mice: implications for immunotherapy of recurrent HSV infection. Vaccine 13: 1706-1712.

43. Manickan E and Rouse BT (1995) Roles of different T-cell subsets in contro of herpes simplex virus infection determined by using T-cell-deficient mousemodels. Journal of virology 69: 8178-8179.

44. Daheshia M, Feldman LT, Rouse BT (1998) Herpes simplex virus latency and the immune response. Curr Opin Microbiol 1: 430-435.

45. Schmid DS, Rouse BT (1992) The role of T cell immunity in control of herpes simplex virus. Curr Top Microbiol Immunol 179: 57-74.

46. Goel N, Mao H, Rong Q, Docherty JJ, Zimmerman D, et al. (2002) The ability of an HSV strain to initiate zosteriform spread correlates with its neuroinvasive disease potential. Arch Virol 147: 763-773

47. Trinchieri G, Pflanz S, Kastelein RA (2003) The IL-12 family of heterodimeric cytokines: new players in the regulation of T cell responses. Immunity 19: 641-644.

48. WHO (2003) Factsheet 211: influenza. World Health Organization. 
Citation: Zimmerman DH, Steiner H, Carmabula R, Talor E, Rosenthal KS (2012) LEAPS Therapeutic Vaccines as Antigen Specific Suppressors of Inflammation in Infectious and Autoimmune Diseases. J Vaccines Vaccin 3:147. doi:10.4172/2157-7560.1000149

49. WHO (2008) Global influenza surveillance. World Health Organization.

50. Carrat F, Flahault A (2007) Influenza vaccine: the challenge of antigenic drift. Vaccine 25: 6852-6862

51. Uger RA, Chan SM, Barber BH (1999) Covalent linkage to beta2-microglobulin enhances the MHC stability and antigenicity of suboptimal CTL epitopes. J Immunol 162: 6024-6028.

52. Deliyannis G, Jackson DC, Ede NJ, Zeng W, Hourdakis I, et al. (2002) Induction of long-term memory CD8(+) T cells for recall of viral clearing responses against influenza virus. J Virol 76: 4212-4221.

53. Chen W, Anton LC, Bennink JR, Yewdell JW (2000) Dissecting the multifactorial causes of immunodominance in class I-restricted $T$ cell responses to viruses. Immunity 12: 83-93.

54. Fan J, Liang X, Horton MS, Perry HC, Citron MP, et al. (2004) Preclinical study of influenza virus A M2 peptide conjugate vaccines in mice, ferrets, and rhesus monkeys. Vaccine 22: 2993-3003.

55. Mozdzanowska K, Feng J, Eid M, Kragol G, Cudic M, et al. (2003) Induction of influenza type A virus-specific resistance by immunization of mice with a synthetic multiple antigenic peptide vaccine that contains ectodomains of matrix protein 2. Vaccine 21: 2616-2626.

56. Reid AH, Fanning TG, Janczewski TA, McCall S, Taubenberger JK (2002) Characterization of the 1918 "Spanish" influenza virus matrix gene segment. J Virol 76: 10717-10723.

57. Feng J, Zhang M, Mozdzanowska K, Zharikova D, Hoff H, et al. (2006) Influenza A virus infection engenders a poor antibody response against the ectodomain of matrix protein 2. Virology Journal 3: 102.
58. Zhang M, Zharikova D, Mozdzanowska K, Otvos L and Gerhard W (2006) Fine specificity and sequence of antibodies directed against the ectodomain of matrix protein 2 of influenza A virus. Molecular immunology 43: 21952206.

59. Zharikova D, Mozdzanowska K, Feng J, Zhang M, Gerhard W (2005) Influenza type $A$ virus escape mutants emerge in vivo in the presence of antibodies to the ectodomain of matrix protein 2. J Virol 79: 6644-6654.

60. Prabhu N, Prabakaran M, Ho HT, Velumani S, Qiang J, et al. (2009) Monoclonal antibodies against the fusion peptide of hemagglutinin protect mice from lethal influenza A virus H5N1 infection. J Virol 83: 2553-2562.

61. Ekiert DC, Bhabha G, Elsliger MA, Friesen RH, Jongeneelen M, et al. (2009) Antibody recognition of a highly conserved influenza virus epitope. Science 324: $246-251$.

62. Tan PT, Khan AM, August JT (2011) Highly conserved influenza A sequences as $T$ cell epitopes-based vaccine targets to address the viral variability. Hum Vaccin 7: 402-409.

63. Sui J, Hwang WC, Perez S, Wei G and Aird D, et al. (2009) Structural and functional bases for broad-spectrum neutralization of avian and human influenza A viruses. Nature structural \& molecular biology 16: 265-273.

64. Pleguezuelos O, Robinson S, Stoloff GA, Caparros-Wanderley W (2012) Synthetic Influenza vaccine (FLU-v) stimulates cell mediated immunity in a double-blind, randomised, placebo-controlled Phase I trial. Vaccine 30: 46554660

65. Frick JS, Grunebach F, Autenrieth IB (2010) Immunomodulation by semimature dendritic cells: a novel role of Toll-like receptors and interleukin-6. Int $J$ Med Microbiol 300: 19-24. 